\title{
Mitiglinide, a Novel Oral Hypoglycemic Agent, Preserves the Cardioprotective Effect of Ischemic Preconditioning in Isolated Perfused Rat Hearts
}

\author{
Kazuhiko OGAwA, ${ }^{1} \mathrm{MD}$, Katsunori IKEwaKI, ${ }^{1} \mathrm{MD}$, Ikuo TANIGUCHI, ${ }^{1} \mathrm{MD}$, \\ Hisashi TAKATSUKA, ${ }^{1} \mathrm{MD}$, Chikara MoRI, ${ }^{1} \mathrm{MD}$, Hideki SASAKI, ${ }^{1} \mathrm{MD}$, \\ Fumiko OKAZAKI, ${ }^{1}$ MD, Mitsuyuki ShIMIZU, ${ }^{1}$ MD, \\ and Seibu MOCHIZUKI, ${ }^{1} \mathrm{MD}$
}

\section{SUMMARY}

Diabetic patients often have manifestation of coronary heart disease. As a consequence, therapeutic strategies for diabetes should pay more attention to hypoglycemic agents which do not have adverse effects on myocardium. Mitiglinide is considered to have little or no impact on the cardioprotective effect of ischemic preconditioning (IP) because of its high selectivity for blocking sulfonylurea receptor1 (SUR1). However, glibenclamide, a nonselective SUR blocker, attenuates this beneficial effect.

In the present study, we tested the hypothesis that mitiglinide preserves the protective action of IP evaluated by ischemia/reperfusion ventricular tachyarrhythmia (rVT) in isolated perfused rat hearts. After initial perfusion, the hearts were assigned to one of the following groups: 1) non-IP with control perfusion buffer (non-IP group); 2) IP with control perfusion buffer (IP-C group); 3) IP with perfusion buffer containing glibenclamide (IPG group); and 4) IP with perfusion buffer containing mitiglinide (IP-M group). The protocol for the non-IP group consisted of 21 minutes of aerobic perfusion before 10 minutes of ischemia. In the other 3 groups (IP groups), there were 3 cycles of 2-minute ischemia followed by 5 minutes of reperfusion before 10 minutes of ischemia. The IP-C group had a significantly shorter rVT duration than the non-IP group (4.4 \pm 1.8 minutes versus 14.3 \pm 2.5 minutes; $P<0.05)$. rVT duration was the shortest in the IP-M group $(3.9 \pm 1.0$ minutes), but among the longest in the IP-G group (14.0 \pm 2.6 minutes).

In conclusion, mitiglinide preserved the cardioprotective effect of IP, however, glibenclamide abolished this beneficial effect. Therefore, mitiglinide may offer a long-term benefit for myocardial ischemia in diabetic patients. (Int Heart J 2007; 48: 337-345)

Key words: Mitiglinide, Glibenclamide, Sulfonylurea Receptors, Ischemic preconditioning, Cardioprotective effect, Ischemia/reperfusion ventricular tachyarrhythmia, Isolated perfused rat hearts

From the ${ }^{1}$ Division of Cardiology, Department of Internal Medicine, The Jikei University School of Medicine, Tokyo, Japan.

Address for correspondence: Kazuhiko Ogawa, MD, Division of Cardiology, Department of Internal Medicine, The Jikei University School of Medicine, 25-8, Nishishinbashi 3-chome, Minato-ku, Tokyo 105-8461, Japan.

Received for publication February 1, 2007.

Revised and accepted April 19, 2007. 
SULFONYLUREA receptors (SUR), which compose the ATP-dependent K channel $\left(\mathrm{K}_{\mathrm{ATP}}\right.$ channel), have 3 subtypes with differing distributions: SUR1 are present in pancreas $\beta$ cells, SUR2A in cardiac myocytes, and SUR2B in vascular smooth muscle cells (Figure 1) ${ }^{1)}$ Since SUR2A on myocardial sarcolemma and mitochondria have been considered to play an important role in the preservation of cardioprotection under ischemic conditions, drugs which block SUR2A may lose this beneficial action. Among the oral hypoglycemic sulfonylurea agents (SUs), some are selective for SUR subtypes while others are not. Therefore, more attention should be paid to potential differences among SUs in terms of their cardioprotective actions during ischemia. ${ }^{2)}$ On the other hand, a preceding brief episode of myocardial ischemia increases the ischemic tolerance of myocardium and prevents myocardial dysfunction caused by a subsequent sustained ischemic insult. This is known as ischemic preconditioning (IP). ${ }^{3}$ Glibenclamide, an oral hypoglycemic agent and nonselective blocker of the SUR, has been shown to diminish the cardioprotection afforded by IP. ${ }^{4)}$

In this study, we examined how mitiglinide, a novel oral hypoglycemic agent that selectively blocks SUR1, affects the protective action of IP against myocardial ischemia/reperfusion injury using an indicator of ischemia/reperfusion ventricular tachyarrhythmia (rVT). We also compared mitiglinide and glibenclamide in this regard in order to assess how SUs with differing SUR selectivity affect cardiac myocytes.

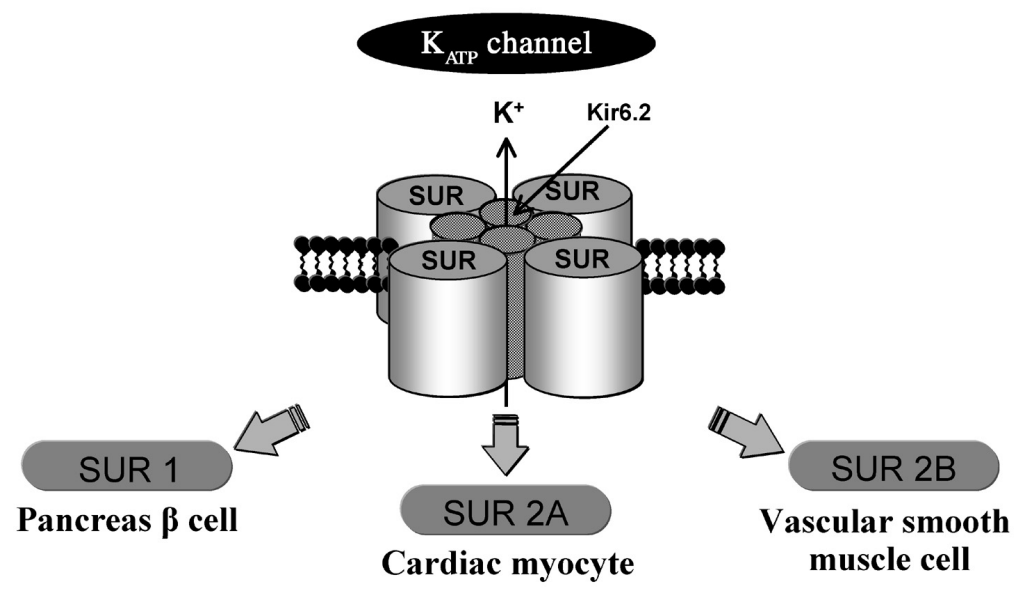

Figure 1. Structure of $K_{\text {ATP }}$ channel and its subunits. $K_{\text {ATP }}$ channels are composed of 2 types of subunits, inwardly rectifying $\mathrm{K}^{+}$channels (Kir6.x) and sulfonylurea receptors (SURx), arranged as tetradimeric complexes, (Kir6.x/SURx) 4 


\section{METHODS}

Experimental animals and perfusion apparatus: Male Sprague-Dawley rats weighing about $400 \mathrm{~g}(399.5 \pm 15.7 \mathrm{~g})$ were used. The rats were anesthetized with pentobarbital $50 \mathrm{mg} / \mathrm{kg}$ intraperitoneally and then the heart was promptly removed and perfused with $80 \mathrm{mmHg}$ under constant pressure. Perfusion was subsequently performed by means of the working heart method as previously described, ${ }^{5)}$ with the preload set to $10 \mathrm{mmHg}$ and the afterload to $80 \mathrm{mmHg}$. A ball valve fitted to the cannula was used to block coronary perfusion during diastole, thereby producing myocardial ischemia. Electrical pacing $(300 \mathrm{bpm}, 3 \mathrm{~V})$ was performed during ischemia.

The concentrations of mitiglinide and glibenclamide in perfusion buffer were selected by referring to previous reports. ${ }^{6,7)}$ All experimental procedures and protocols used in this study were reviewed and approved by the Animal Experiment Committee of The Jikei University School of Medicine.

Evaluation of ischemia/reperfusion ventricular tachyarrhythmia (rVT) and left ventricular function: Throughout the experiment, electrocardiograms were recorded via a carbon lead attached to the surface of the heart. The electrocardiograms recorded the incidence and duration of rVT, such as sustained ventricular tachycardia and ventricular fibrillation that occurred after reperfusion. These were used as indicators of the severity of myocardial ischemia/reperfusion injury as

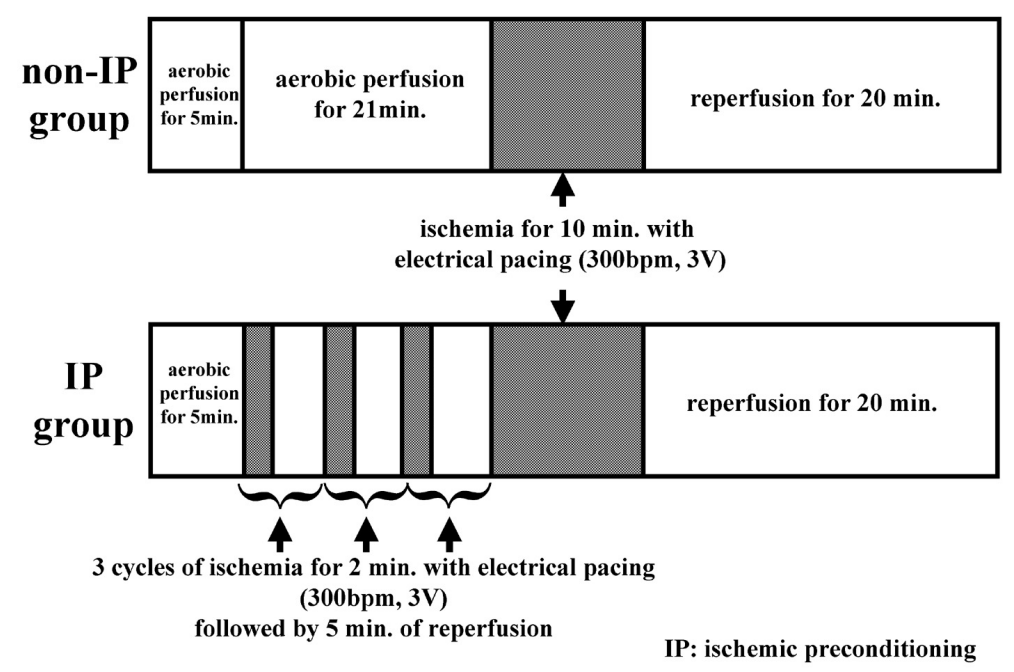

Figure 2. Perfusion protocol. After 5 minutes of initial aerobic perfusion, the non-IP group received 21 minutes of aerobic perfusion before 10 minutes of ischemia, while the IP groups (IP-C group, IP-G group and IP-M group) received 3 cycles of a 2 -minute ischemia followed by 5 minutes of reperfusion before 10 minutes of ischemia. 
well as the cardioprotective effect of IP. Simultaneously, an 18-gauge catheter was inserted into the left ventricle through the left atrium. Left ventricular pressure (LVP), $L V$ max $+\mathrm{dP} / \mathrm{dt}(\mathrm{LV}+\mathrm{dP} / \mathrm{dt})$, and $\mathrm{LV} \max -\mathrm{dP} / \mathrm{dt}(\mathrm{LV}-\mathrm{dP} / \mathrm{dt})$ were measured in the catheter using a polygraph system (FUKUDA DENSHI CO., LTD., Tokyo).

Perfusion buffers: Two perfusion buffers, one containing $10^{-7} \mathrm{Mol}$ glibenclamide and the other $2 \times 10^{-6} \mathrm{Mol}$ mitiglinide, were prepared using modified KrebsHenseleit bicarbonate buffer ( $\mathrm{pH} 7.4, \mathrm{~K}=4.5 \mathrm{MEq})$ as control perfusion buffer. Protocol of ischemic preconditioning and ischemia/reperfusion (Figure 2): All hearts underwent 5 minutes of initial aerobic perfusion. Subsequently, hearts without IP underwent another 21 minutes of aerobic perfusion before 10 minutes of ischemia followed by 20 minutes of reperfusion. Hearts with IP underwent 3 cycles of a 2-minute ischemia followed by a 5-minute reperfusion before $10 \mathrm{~min}$ utes of ischemia followed by 20 minutes of reperfusion.

Grouping: The rat hearts were divided into the following 4 groups according to the presence or absence of IP and the type of perfusion buffer. 1) non-IP group: non-IP performed with control perfusion buffer, 2) IP-C group: IP performed with control perfusion buffer, 3) IP-G group: IP performed with perfusion buffer containing glibenclamide, and 4) IP-M group: IP performed with perfusion buffer containing mitiglinide.

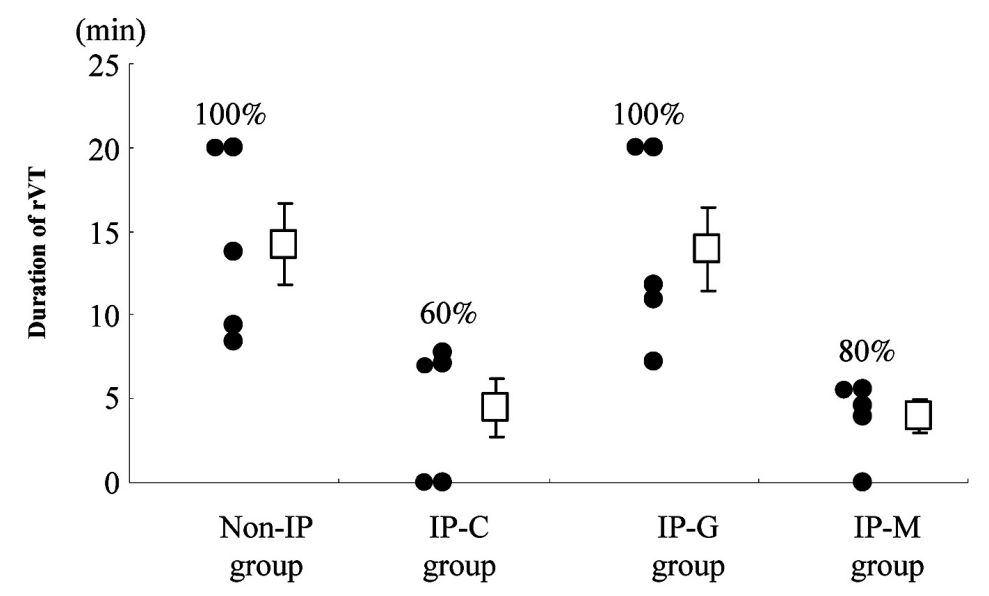

Figure 3. Incidence and mean duration of rVT. $\bigcirc$ represents the duration of rVT in each rat and $\square$ represents mean duration of rVT in each group. Y axis shows time (sec). The percentages in the graph indicate the incidence of rVT in each group. 
Statistic analysis: All data are expressed as the mean \pm SEM and were analyzed using ANOVA followed by Scheffé's procedure. The incidence of rVT was analyzed using the chi-square test. A $P<0.05$ was considered to be statistically significant. All statistical procedures were performed using SPSS software (version 9.1, SPSS Inc. Chicago, IL).

\section{RESULTS}

Incidence and mean duration of rVT (Figure 3): $\mathrm{rVT}$ appeared in all 5 hearts $(100 \%)$ in the non-IP group and in 3 of the 5 hearts (60\%) in the IP-C group. The incidence of rVT was all 5 hearts $(100 \%)$ in the IP-G group and 4 of the 5 hearts $(80 \%)$ in the IP-M group. There were no significant differences among the groups with respect to the incidence of rVT.

The mean duration of sustained rVT was significantly shorter in the IP-C group than that in the non-IP group $(4.4 \pm 1.8$ minutes versus $14.3 \pm 2.5$ minutes, $P<0.05)$, indicating the cardioprotective effect of IP. Further, although not sig-
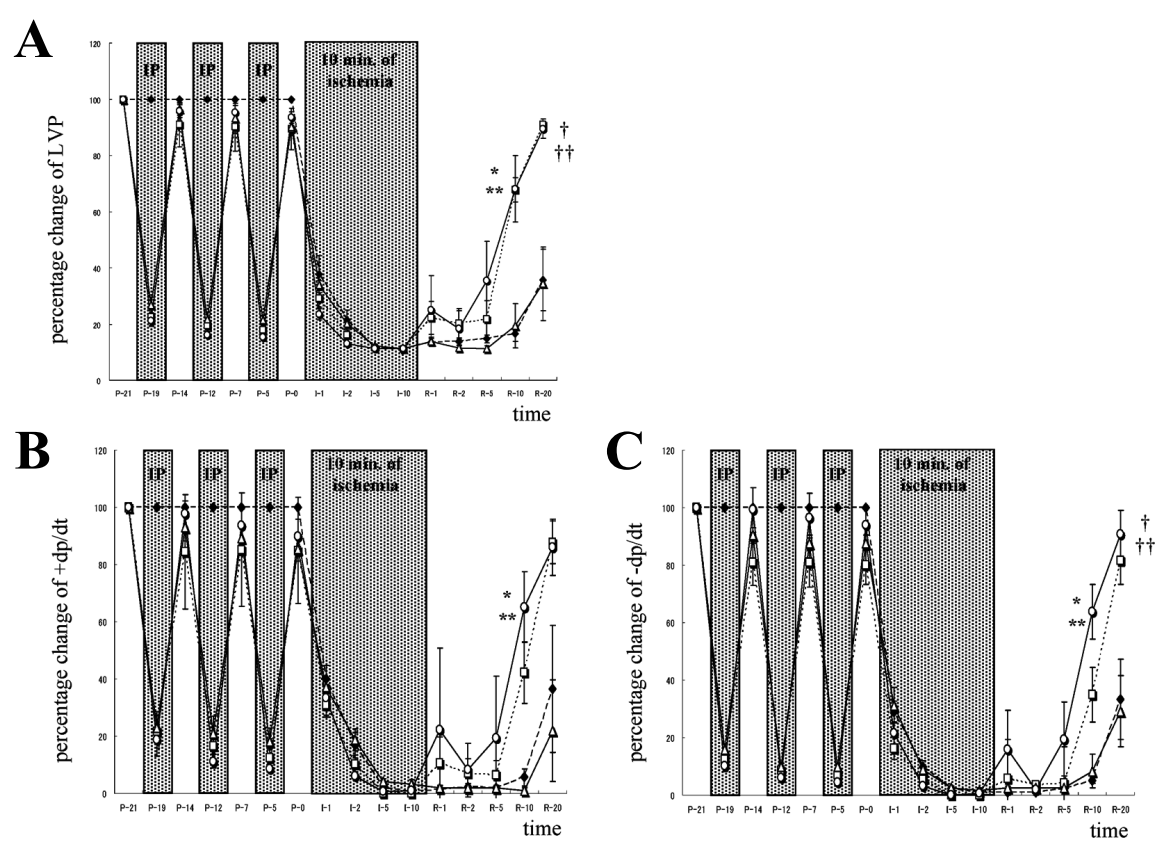

Figure 4. Time course of percent changes for functional recovery of LV after reperfusion. A, B and C: percentage change in $\mathrm{LV}$ pressure, $+\mathrm{dp} / \mathrm{dt}$, and $-\mathrm{dp} / \mathrm{dt}$, respectively. IP: ischemic preconditioning; $\bullet$ : non-IP group, $\square$ : IP-C group, $\triangle$ : IP-G group, O: IP-M group; $*<0.05$ versus the non-IP group after 10 minutes of reperfusion, $* *<0.05$ versus the IP-G group after 10 minutes of reperfusion. $\dagger<0.05$ versus the non-IP group after 20 minutes of reperfusion, $\dagger \dagger<0.05$ versus the IP-G group after 20 minutes of reperfusion. $\mathrm{P}, \mathrm{I}$ and $\mathrm{R}$ in $\mathrm{X}$-axis item of each graph means before 10 minutes of ischemia, during 10 minutes of ischemia, and after reperfusion, respectively. Each number represents time (minutes). For example, P-21, I-2 and R-20 represent 21 minutes before 10 minutes of ischemia, 2 minutes of ischemia, and 20 minutes after reperfusion, respectively. Y axis represents percent change. 
nificant, the mean duration in the IP-M group was similar or shorter than that in the IP-C group ( $3.9 \pm 1.0$ minutes). In contrast, the average duration of rVT (14.0 \pm 2.6 minutes) in the IP-G group was comparable to that in the non-IP group.

Recovery of LV function (LVP, \pm dp/dt) (Figure 4): After 10 minutes of ischemia and 20 minutes of reperfusion, the recovery of LV pressure was significantly greater in the IP-M group than in the non-IP group and in the IP-G group. The + $\mathrm{dp} / \mathrm{dt}$ level was also significantly higher in the IP-M group than in the non-IP group and in the IP-G group after 10 minutes of reperfusion. Similarly, the - dp/dt level was significantly higher in the IP-M group than in the non-IP group and in the IP-G group after 10 and 20 minutes of reperfusion.

\section{Discussion}

Patients with type 2 diabetes have significantly increased risk of cardiovascular complications with higher morbidity and mortality compared to their nondiabetic counterparts. ${ }^{8-10)}$ Although the use of sulfonylureas (SUs) in patients with type 2 diabetes is quite common, an increased risk of cardiovascular complications and an increased fatality rate after myocardial infarction have been reported. ${ }^{11)}$ Oral SUs such as glibenclamide, which block $\mathrm{K}_{\mathrm{ATP}}$ channels (SUR1), stimulating insulin release from pancreatic $\beta$-cells, also inhibit the opening of other sarcolemmal $\mathrm{K}_{\text {ATP }}$ channels including cardiac myocytes (SUR2A) and vascular smooth muscle cells (SUR2B), as well as $\mathrm{K}_{\mathrm{ATP}}$ channels on the membrane of mitochondria of cardiac myocytes. Over the last 3 decades, epidemiologic data concerning the cardiac effects of SUs have been changing gradually. Previous studies indicated that "relatively old generation" SUs seemed to be detrimental to the heart, ${ }^{12-14)}$ however, recent studies suggest that "new generation" SUs may be neutral in this respect. ${ }^{15-18)}$ Overall, it remains to be established whether, and if so, which SUs increase the risk of cardiovascular complications in patients with type 2 diabetes. In this context, we investigated the effects of a new oral hypoglycemic agent, mitiglinide, which is relatively selective for SUR1 over SUR2A, in comparison with a nonselective counterpart, glibenclamide. The present data clearly demonstrate that mitiglinide did not inhibit the antiarrhythmic effects of IP on rat hearts, while glibenclamide did.

The rVT duration was significantly shorter when IP was performed using control perfusion buffer. This beneficial effect of IP was preserved in the group that received a perfusion buffer containing mitiglinide. Moreover, the IP-M group also showed greater LV function recovery after 10 minutes of reperfusion than did the IP-G group or the non-IP group. These results suggest that mitiglinide can preserve the cardioprotective effect of IP, whereas glibenclamide abolishes this effect. 
Supporting our favorable effect of mitiglinide relative to glibenclamide, Maruyama, et $a l^{19)}$ reported that mitiglinide did not affect the coronary perfusion volume or the LV function after reperfusion, whereas glibenclamide significantly worsened LV end-diastolic pressure and systolic pressure after reperfusion, using perfused rat hearts. They concluded that mitiglinide has a much smaller impact on the cardiovascular system than glibenclamide. Further, Ichikawa, et $a l^{20}$ described in their report using anesthetized canines that mitiglinide did not affect the recovery of LV function after reperfusion.

The extremely high selectivity of mitiglinide for SUR1 may result in a much smaller impact, if any, on the cardiovascular system. Using the patch clamp method, Reimann, et al examined how mitiglinide affects the channel currents in each SUR subtype and reported that its affinity to SUR1 is 1,000 times greater than that to SUR2A and SUR2B. ${ }^{6}$ Moreover, Sunaga, et al conducted a similar examination and reported that mitiglinide inhibits the SUR1 $\mathrm{K}_{\mathrm{ATP}}$ channel currents at $100 \mathrm{nM}\left(\mathrm{IC}_{50}\right.$ value), but does not inhibit either SUR2A or SUR2B, even at a high dose of $10 \mu \mathrm{M}$, demonstrating the high affinity of mitiglinide for SUR1. ${ }^{21)}$ These observations are thus consistent with the concept that mitiglinide selectively inhibits SUR1.

Myocardial protection of IP involves the opening of both sarcolemmal $\mathrm{K}_{\text {ATP }}$ and mitochondrial $\mathrm{K}_{\mathrm{ATP}}$ channels during ischemia. ${ }^{22,23)}$ Glibenclamide has nonselective affinity to every SUR subtype, as well as blocking the $\mathrm{K}_{\text {ATP }}$ channel opening on the membrane of cardiac mitochondria. ${ }^{4)}$ Therefore, glibenclamide is considered to abolish the cardioprotective action afforded by IP due to its mitochondrial $\mathrm{K}_{\text {ATP }}$ channel blockade in addition to sarcolemmal $\mathrm{K}_{\mathrm{ATP}}$ channel blockade.

On the contrary, mitiglinide does not affect the SUR2A of sarcolemmal $\mathrm{K}_{\text {ATP }}$ channels at the external concentration of $2 \times 10^{-6} \mathrm{M}$ compared with glibenclamide $\left(10^{-7} \mathrm{M}\right)$ and therefore does not interfere with the opening of the $\mathrm{K}_{\mathrm{ATP}}$ channels in the myocardium during ischemia. Based on these reports, mitiglinide is expected to have a much smaller impact on cardiac myocytes than glibenclamide and this is exactly what we observed in the present study.

There are limitations in this study. We simultaneously measured arrhythmic sustain times and cardiac function. However, the presence of rVT greatly affected the LV function: ie, when rVT occurs, effective cardiac contraction disappears, resulting in LV pressure becoming not measurable. In this regard, improved LV function recovery can be a consequence of the improved antiarrhythmic effect. Therefore, in order to precisely observe the recovery of cardiac function, we need to either compare LV function after rVT returns to sinus rhythm with electrical defibrillation during reperfusion or to perform a study using another protocol which involves little or no arrhythmia. Because mitiglinide is different from SUs, 
both cannot be compared only from the point of view of the difference in the selectivity for SU receptors. Further study is needed in the future to compare mitiglinide with SUs with respect to other cardiovascular pharmacological actions besides SU receptor blocking.

In conclusion, oral hypoglycemic agents with a nonselective SUR inhibitory effect fail to preserve the cardioprotective effect afforded by IP, a potential reason for the increased risk of cardiovascular events as previously reported. ${ }^{11)}$ On the other hand, mitiglinide, a novel oral hypoglycemic agent with high selectivity for SUR1, does preserve the cardioprotective effect of IP, presumably via the unblocking of $\mathrm{K}_{\text {ATP }}$ channels of cardiac myocytes and vascular smooth muscle cells. Accordingly, drugs that selectively block SUR1, such as mitiglinide, are expected to provide a clinical benefit in diabetic patients, in particular when coronary heart disease is a complication.

\section{ACKNOWLEDGEMENTS}

We are deeply indebted to Kissei Pharmaceutical Company for kindly providing the mitiglinide and supporting the study.

\section{REFERENCES}

1. Quast U, Stephan D, Bieger S, Russ U. The impact of ATP-sensitive $\mathrm{K}^{+}$channel subtype selectivity of insulin secretagogues for the coronary vasculature and the myocardium. Diabetes 2004; 53: S156-64. (Review)

2. Meier JJ, Gallwitz B, Schmidt WE, Mugge A, Nauck MA. Is impairment of ischaemic preconditioning by sulfonylurea drugs clinically important? Heart 2004; 90: 9-12. (Review)

3. Murry CE, Jennings RB, Reimer KA. Preconditioning with ischemia: a delay of lethal cell injury in ischemic myocardium. Circulation 1986; 74: 1124-36.

4. Mocanu MM, Maddock HL, Baxter GF, Lawrence CL, Standen NB, Yellon DM. Glimepiride, a novel sulfonylurea, does not abolish myocardia protection afforded by either ischemic preconditioning or diazoxide. Circulation 2001; 103: 3111-6.

5. Neely JR, Rovetto MJ, Whitmer JT, Morgan HE. Effects of ischemia on function and metabolism of the isolated working rat heart. Am J Physiol 1973; 225: 651-8.

6. Reimann F, Proks P, Ashcroft FM. Effects of mitiglinide (S21403) on Kir6.2/SUR1, Kir6.2/SUR2A and Kir6.2/SUR2B types of ATP-sensitive potassium channel. Br J Pharmacol 2001; 132: 1542-8.

7. Proks P, Reimann F, Green N, Gribble F, Ashcroft F. Sulfonylurea stimulation of insulin secretion. Diabetes 2002; 51: S368-76. (Review)

8. Beckman JA, Creager MA, Libby P. Diabetes and atherosclerosis: epidemiology, pathophysiology, and management. JAMA 2002; 287: 2570-81. (Review)

9. Rytter L, Troelsen S, Beck-Nielsen H. Prevalence and mortality of acute myocardial infarction in patients with diabetes. Diabetes Care 1985; 8: 230-54.

10. Cooper RS, Pacold IV, Ford ES. Age-related differences in case-fatality rates among diabetic patients with myocardial infarction. Findings from National Hospital Discharge Survey, 1979-1987. Diabetes Care 1991; 14: 903-8.

11. Thisted H, Johnsen SP, Rungby J. Sulfonylureas and the risk of myocardial infarction. Metabolism 2006; 55 : S16-9. 
12. Hadden DR, Montgomery DA, Weaver JA. Myocardial infarction in maturity-onset diabetics. A retrospective study. Lancet 1972; 1: 335-8.

13. Soler NG, Pentecost BL, Bennett MA, FitzGerald MG, Lamb P, Malins JM. Coronary care for myocardial infarction in diabetics. Lancet 1974; 1: 475-7.

14. Gustafsson I, Hildebrandt P, Seibaek M, et al. Long-term prognosis of diabetic patients with myocardial infarction: relation to antidiabetic treatment regimen. The TRACE Study Group. Eur Heart J 2000; 21: 1937-43.

15. UK Prospective Diabetes Study (UKPDS) Group. Intensive blood-glucose control with sulfonylureas or insulin compared with conventional treatment and risk of complications in patients with type 2 diabetes (UKPDS 33). Lancet 1998; 352: 837-53.

16. Klamann A, Sarfert P, Launhardt V, Schulte G, Schmiegel WH, Nauck MA. Myocardial infarction in diabetic vs non-diabetic subjects. Survival and infarct size following therapy with sulfonylureas (glibenclamide). Eur Heart J 2000; 21: 220-9.

17. Davis TM, Parsons RW, Broadhurst RJ, Hobbs MS, Jamrozik K. Arrhythmia and mortality after myocardial infarction in diabetic patients. Relationship to diabetes treatment. Diabetes Care 1998; 21: 637-40.

18. Stevens RJ, Coleman RL, Adler AI, Stratton IM, Matthews DR, Holman RR. Risk factor for myocardial infarction case fatality and stroke case fatality in type 2 diabetes: UKPDS 66. Diabetes Care 2004; $27: 201-7$.

19. Maruyama I, Tomiyama Y, Maruyama K, et al. Effects of mitiglinide and sulfonylureas in isolated canine coronary arteries and perfused rat hearts. Eur J Pharmacol 2006; 531: 194-200.

20. Ichikawa K, Maruyama K, Murakami M, et al. Absence of exacerbation of myocardial stunning in anesthetized dogs treated with KAD-1229, a novel hypoglycemic agent. Eur J Pharmacol 2001; 431: 331-8.

21. Sunaga Y, Gonoi T, Shibasaki T, et al. The effects of mitiglinide (KAD-1229), a new anti-diabetic drug, on ATP-sensitive $\mathrm{K}^{+}$channels and insulin secretion: comparison with the sulfonylureas and nateglinide. Eur $\mathrm{J}$ Pharmacol 2001; 431: 119-25.

22. Tanno M, Miura T, Tsuchida A, et al. Contribution of both the sarcolemmal K (ATP) and mitochondrial K (ATP) channels to infarct size limitation by K (ATP) channel openers: difference from preconditioning in the role of sarcolemmal K (ATP) channels. Naunyn Schmiedebergs Arch Pharmacol 2001; 364: 226-32.

23. Tsuchida A, Miura T, Tanno M, et al. Infarct size limitation by nicorandil: roles of mitochondrial K (ATP) channels, sarcolemmal K (ATP) channels, and protein kinase C. J Am Coll Cardiol 2002; 40: 1523-30. 